\title{
Revista AzMina e o jornalismo como forma de conhecimentol
}

\section{Gabriela Braga Schander² \\ Daiane Bertasso 3}

\section{Resumo}

Este artigo apresenta como objeto de estudo a produção de conhecimento nos discursos produzidos por uma revista feminista brasileira. O objetivo é perceber qual é o jornalismo produzido por uma mídia autointitulada independente e feminista, e se este é orientado pela ideia da produção de conhecimento. $O$ objeto empírico é a Revista AzMina, sendo o corpus constituído de reportagens veiculadas no site. A pesquisa utiliza a análise discursiva como aporte teóricometodológico. Dentre as considerações finais do estudo tem-se a percepção de que 0 jornalismo feminista de AzMina, combativo, ideologicamente comprometido e posicionado, é uma das formas de se fazer conhecer mulheres e assuntos invisibilizados pela mídia tradicional e de ser uma prática de fato orientada pela ideia de conhecimento.

Palavras-chave: Gênero. Jornalismo feminista. Revista AzMina.

\section{Revista AzMina and the journalism as a form of knowledge}

\section{Abstract}

This article presents as object of study the knowledge production in the discourses produced by a brazilian feminist magazine. Objective is to perceive what is the journalism produced by a self-titled independent and feminist media and if this is oriented by the idea of knowledge production. Empiric object is Revista AzMina and the corpus constituted by published reports on the website. The research uses discursive analysis as a theoretical-methodological contribute. Among the final

\footnotetext{
U Uma primeira versão deste artigo foi apresentada no $6^{\circ}$ Colóquio Mulher e Sociedade, ocorrido entre os dias 23 e 24 de abril de 2019 na Universidade Estadual de Ponta Grossa (UEPG), Ponta Grossa/PR.

${ }_{2}^{2}$ Mestranda do Programa de Pós-Graduação em Jornalismo da Universidade Federal de Santa Catarina (UFSC). Bolsista CAPES. E-mail: gabischander@gmail.com.

3Professora adjunta no Departamento de Jornalismo da Universidade Federal de Santa Catarina (UFSC) e no Programa de Pós-Graduação em Jornalismo (POSJOR/UFSC). E-mail: daianebertasso@gmail.com.
}

Revista Pauta Geral-Estudos em Jornalismo, Ponta Grossa, vol. 6, n. 2, p. 35-52, Jul/Dez, 2019. 


\section{REVISTA PAUTA GERAL}

\section{ESTUDOS EM JORNALISMO}

10.5212/RevistaPautaGeral.v.6.i2.0003

considerations of the study is the perception that AzMina feminist journalism (combative, ideologically compromised and positioned) is one of the ways of getting to know women and invisible subjects by traditional media and to be a practice, in fact, oriented by the idea of knowledge.

Keywords: Gender. Feminist journalism. Revista AzMina.

\section{Introdução}

A pesquisa realizada ${ }^{4}$ em 2017 pela Associação Brasileira de Jornalismo Investigativo (Abraji) e a Gênero e Número identificou altos índices de assédio e violência presentes nas rotinas de trabalho das jornalistas brasileiras. As estatísticas apontam que 92,3\% das entrevistadas afirmaram já terem ouvido piadas machistas em ambientes de trabalho e $83,6 \%$ já sofreram algum tipo de violência psicológica nas redações. Em vista desses e outros resultados obtidos, o estudo conclui que a igualdade de gênero ainda é um impasse recorrente e um obstáculo a ser superado pelas redações jornalísticas.

Diante desse cenário profissional desagradável, somado ao histórico afastamento das mulheres na participação discursiva (SILVEIRINHA, 2012), iniciativas jornalísticas gerenciadas por mulheres começam a ser impulsionadas. A Revista AzMina, objeto empírico deste artigo, é um desses exemplos. Surgida em 2015 na internet, foi ganhadora do Troféu Mulher Imprensa em junho de 2017 pela categoria "Melhor Projeto Jornalístico". Hoje, conta com mais de 132 mil curtidas na página oficial do Facebook, e é uma das revistas de referência para o público feminista. Mas que jornalismo é este que está sendo produzido por ela?

Com o intuito de problematizar essa ideia, o objetivo desta pesquisa é compreender se o fazer jornalístico de um veículo de comunicação autointitulado independente e feminista está orientado pela ideia da produção de conhecimento e, em caso positivo, como se percebe este conhecimento e qual seu "tipo", conforme reflexão proposta por Genro Filho (2012). Assim, ficam os seguintes questionamentos: esse veículo está mesmo produzindo conhecimento? E, mais em específico, que conhecimentos podem ser produzidos por uma mídia autodeclarada feminista?

${ }^{4}$ GÊNERO E NÚMERO; ABRAJI. MUlheres no jornalismo brasileiro. 2017. Disponível em: $<$ https://www.mulheresnojornalismo.org.br/12901 GN relatorioV4.pdf/>. Acesso em: 1 fev. 2019.

Revista Pauta Geral-Estudos em Jornalismo, Ponta Grossa, vol. 6, n. 2, p. 35-52, Jul/Dez, 2019. 


\section{REVISTA PAUTA GERAL}

\section{ESTUDOS EM JORNALISMO}

10.5212/RevistaPautaGeral.v.6.i2.0003

A partir disso, ter como objeto de estudo a produção de conhecimento nos discursos produzidos por uma mídia feminista implica em um entendimento do feminismo enquanto movimento político-social que provoca uma ação e reflexão teórica. Nos identificarmos enquanto pesquisadoras feministas filiadas ao campo temático dos estudos feministas sugere questionamentos aos paradigmas tradicionais adotados pela ciência. Também é uma maneira de endossar a perspectiva de afirmação das mulheres como sujeitas do conhecimento (ZIRBEL, 2007) tanto no viés da produção de um material científico quanto na pesquisa de uma prática jornalística realizada por mulheres a qual se supõe orientada pelo conhecimento.

Tendo como horizonte concepções teóricas feministas (NARVAZ; KOLLER, 2006), utilizamos a Análise de Discurso de linha francesa como aporte teórico-metodológico, bem como as SDs (sequências discursivas) de trechos das reportagens e a técnica de entrevista com uma das jornalistas da revista como materiais qualitativos. Nesta pesquisa, foram acessadas todas as reportagens presentes nas 15 subseções das "Reportagens" e nas 17 reportagens da seção "Especiais" desde a criação de AzMina, no período entre maio de 2015 a janeiro de 20195. A partir da análise desses materiais jornalísticos, pretendemos tensionar uma proposta analítica que possibilite indicar potencialidades no que se refere às noções de conhecimento acerca de um fazer jornalístico autodenominado feminista.

\section{Jornalismo como conhecimento}

A questão do jornalismo e sua relação com o conhecimento admite variadas abordagens (MEDITSCH, 2002). Neste artigo, adotamos a perspectiva do jornalismo enquanto uma forma de conhecimento (GROTH, 2011; PARK, 2008) e, principalmente, a função social de produção desse conhecimento (GENRO FILHO, 2012).

A partir dessa concepção, o jornalismo passa a ser posicionado no centro da produção de conhecimento. Esse, por sua vez, não se configura em moldes positivistas, mas como uma práxis, dimensão simbólica da apropriação da sujeita sobre a realidade (PONTES, 2012). Assim, Genro Filho (2012) sugere pensar o jornalismo por meio de uma

\footnotetext{
5Identificamos as dez temáticas mais recorrentes, a saber: aborto, negritude, assédio, estupro, deficiência, transexualidade, maternidade, representação feminina na política, indígena, questões relacionadas ao corpo. Importante destacar que existem assuntos que perpassam diferentes reportagens, por exemplo, questões referentes à política.
}

Revista Pauta Geral-Estudos em Jornalismo, Ponta Grossa, vol. 6, n. 2, p. 35-52, Jul/Dez, 2019. 


\section{REVISTA PAUTA GERAL}

\section{ESTUDOS EM JORNALISMO}

10.5212/RevistaPautaGeral.v.6.i2.0003

conexão com categorias filosóficas, "situando os aspectos histórico-sociais no contexto de uma reflexão de alcance ontológico sobre o desenvolvimento social” (GENRO FILHO, 2012, p. 162). Como base teórica, recupera as categorias do singular, particular e universal - estabelecidas por Hegel e apropriadas por Lukács -, e propõe uma concepção materialista da práxis a partir delas como modalidade do conhecimento.

Nessa apropriação das categorias, em que Lukács refere à arte a particularidade e à ciência a universalidade, Genro Filho (2012) propõe o jornalismo relacionado à singularidade, a qual se manifestaria na atmosfera da imediaticidade compartilhada e da experiência vivida. O singular torna-se a matéria-prima do jornalismo. O critério jornalístico de uma informação então se vincula à reprodução de um evento a partir do ângulo de sua singularidade.

Em um debate contemporâneo complementar às ideias de Genro Filho, Eduardo Meditsch assenta sua perspectiva em influências freirianas, e discute essa questão "reafirmando o jornalismo como conhecimento social permeado por visões de mundo e ideologias" (VEIGA DA SILVA, 2014, p. 58). Tais proposições levam em conta a dimensão política e a participação dos valores e conhecimentos das jornalistas como parte do processo de produção das notícias.

A questão também se centra no fato do conteúdo do jornalismo estar vinculado a um contexto. Os sentidos mobilizados são condicionados histórica e culturalmente por contextos, bem como pela subjetividade daquelas que os produzem. Diante isso, Meditsch (2002) aponta que a falta de transparência acerca dos condicionantes que fazem parte do processo de produção se apresenta como um obstáculo na ideia de jornalismo como conhecimento. Portanto, uma das inferências que se chega é a mesma já apontada por Genro Filho (2012): nem todo jornalismo pode ser considerado conhecimento.

De maneira sucinta, uma prática jornalística orientada à produção de conhecimento dialoga com a percebida por Marcia Veiga da Silva (2014):

Da instância pedagógica cultural representada pela mídia, o jornalismo é um dos principais articuladores da produção dos saberes cotidianos que orientam a (e se orientam na) cultura. A função pedagógica do jornalismo pode ser percebida na reprodução e circulação do acervo dos conhecimentos socialmente construídos e culturalmente legitimados que ajudam a informar os sujeitos na contemporaneidade. Sua função "educativa" se traduz, sobretudo, pela necessidade de "explicar" o mundo sempre baseado na "verdade" e fazendo uso de recursos técnicos e humanos capazes de ilustrarem esses saberes gerando significados. $O$

Revista Pauta Geral-Estudos em Jornalismo, Ponta Grossa, vol. 6, n. 2, p. 35-52, Jul/Dez, 2019. 


\section{REVISTA PAUTA GERAL}

\section{ESTUDOS EM JORNALISMO}

10.5212/RevistaPautaGeral.v.6.i2.0003

jornalismo é, na perspectiva aqui adotada, um conhecimento social e cultural que ensina. (VEIGA DA SILVA, 2014, p. 56)

A discussão do jornalismo como forma de conhecimento traz a relevância do campo na produção simbólica, de forma a indicar que as notícias são envolvidas por visões de mundo que contribuem cultural e socialmente como forma de orientação sobre os parâmetros e valores circulantes na sociedade (VEIGA DA SILVA, 2014). O processo de gerar e dar significados por meio da produção de notícias torna evidente a participação do jornalismo na construção das realidades sociais.

Assim, "o jornalismo se estabelece como um lócus de poder-saber da contemporaneidade, sobretudo no que se refere aos modos legítimos e ilegítimos de ser sujeito em determinada cultura" (VEIGA DA SILVA, 2014, p. 60). Isso se traduz numa dificuldade de pensar a cultura em que estamos inseridas sem refletir o papel do jornalismo nela exercido, no qual normatiza a sociedade e participa dos processos pelos quais são valoradas as relações sociais.

\section{Discurso e a questão de gênero}

Para compor essa discussão, partimos das concepções teóricas abarcadas pelos estudos feministas ${ }^{6}$. Essas investigações, que abarcam um viés não sexista, referem-se "à inclusão dos aspectos de gênero e de poder na construção do conhecimento" (NARVAZ; KOLLER, 2006, p. 651). Dessa forma, algumas proposições são associadas à dimensão discursiva em conformidade com uma concepção teórica feminista, como as proposições de Donna Haraway (1995) a respeito da objetividade.

Ao apoiar-se metaforicamente na visão - "é sempre uma questão do poder ver" (HARAWAY, 1995, p. 25) -, a autora entende a objetividade feminista como "saberes localizados", os quais possibilitam conhecimentos situados e corporificados. Somente a adoção desta perspectiva parcial permitiria uma visão plenamente objetiva, identificando a potência de construção de mundos menos organizados por eixos de dominação.

\footnotetext{
'Os estudos feministas são compostos por diferentes visões teóricas e epistemológicas de discussão que vêm sendo desenvolvidas e incorporadas ao campo temático ao longo do tempo. Atualmente registramos a forte influência dos estudos feministas decoloniais, que apresentam diferentes propostas de pensar a partir das localidades para construir as reflexões dos feminismos contemporâneos.
}

Revista Pauta Geral-Estudos em Jornalismo, Ponta Grossa, vol. 6, n. 2, p. 35-52, Jul/Dez, 2019. 


\section{REVISTA PAUTA GERAL}

\section{ESTUDOS EM JORNALISMO}

10.5212/RevistaPautaGeral.v.6.i2.0003

Diante dessas proposições, leva-se em conta a agência dos objetos estudados como ativos e geradores de significados. Estes significados, decorrentes de sentidos, são característicos dos discursos derivados de aspectos históricos, sociais e ideológicos tanto do intradiscurso (o dito agora) quanto do interdiscurso (o já-dito) (BENETTI, 2016). Charaudeau (2018) defende que o discurso:

[...] resulta da combinação das circunstâncias em que se fala ou escreve (a identidade daquele que fala e daquele a quem este se dirige, a relação de intencionalidade que os liga e as condições físicas da troca) pela maneira pela qual se fala. É, pois, a imbricação das condições extradiscursivas e das realizações intradiscursivas que produz sentido. (CHARAUDEAU, 2018, p. 40)

As condições de produção do discurso são fundamentais para sua compreensão, bem como para constituição das sujeitas que ocupam o local de enunciação. Depreendese, portanto, que não há sentidos sem sujeitas e sujeitas sem ideologia, o que culmina em um fazer jornalístico marcado pela produção de discursos ideologicamente posicionados.

Se nos localizamos diante de um jornalismo com perspectiva de gênero, a leitura dos fatos depende de onde estamos posicionadas e dos hábitos de nossos olhos (HARAWAY, 1995). "Na maior parte dos casos nós não vemos em primeiro lugar, para então definir, nós definimos primeiro e então vemos" (LIPPMANN, 2008, p. 85) segundo aquilo que já foi captado de forma estereotipada pela cultura. Estes estereótipos resultam dos padrões inclusivos que constituem as próprias filosofias de vida, cernes de uma tradição pessoal e/ou defesa de uma posição na sociedade.

Uma mídia feminista, diante de sua própria construção e desconstrução de outros estereótipos - esses em sua maioria partilhados pela cultura em geral -, constrói seus discursos pensando o gênero como uma forma de significar as relações de poder (SCOTT, 1989) e como parte constituinte da sujeita. Como argumenta Guacira Lopes Louro (1997):

Ao afirmar que o gênero institui a identidade do sujeito (assim como a etnia, a classe, ou a nacionalidade, por exemplo) pretende-se referir, portanto, a algo que transcende o mero desempenho de papéis, a idéia é perceber o gênero fazendo parte do sujeito, constituindo-o. O sujeito é brasileiro, negro, homem, etc. Nessa perspectiva admite-se que as diferentes instituições e práticas sociais são constituídas pelos gêneros e são, também, constituintes dos gêneros. Estas práticas e instituições "fabricam" os sujeitos. Busca-se compreender que a justiça, a igreja, as

Revista Pauta Geral-Estudos em Jornalismo, Ponta Grossa, vol. 6, n. 2, p. 35-52, Jul/Dez, 2019. 


\section{REVISTA PAUTA GERAL}

\section{ESTUDOS EM JORNALISMO}

10.5212/RevistaPautaGeral.v.6.i2.0003

práticas educativas ou de governo, a política, etc. são atravessadas pelos gêneros: essas instâncias, práticas ou espaços sociais são "generificados" - produzem-se, ou "engendram-se", a partir das relações de gênero (mas não apenas a partir dessas relações, e sim, também, das relações de classe, étnicas, etc.). (LOURO, 1997, p. 25)

Ao encontro dessa compreensão, Ana Gabriela Macedo (2011) enuncia, referindose à arte - mas que a ideia pode facilmente ser transposta ao jornalismo -, que intervenções feministas tornam visíveis as necessidades de repensar os modos de representação dominantes. Isso ocorre tanto pelos questionamentos teóricos quanto pelo estranhamento ideológico que o feminismo tem suscitado. Assim, recorrem a uma estratégia de "dês-identificação" que se traduz em rupturas com determinados padrões estabelecidos propondo-se à produção de um discurso crítico de oposição.

Diante dessa proposta de discurso localizado, baseada em uma prática discursiva que passa por um processo enunciativo que requer modos de dizer próprios (BRAGA, 2005), veículos jornalísticos com perspectiva de gênero constroem diferentes leituras afirmadas nas escolhas que envolvem o processo de produção, como as questões dos valores-notícia, as subjetividades e o próprio fazer jornalístico. Assim, entender o discurso desses veículos é tão importante quanto assimilar suas características próprias enquanto revistas feministas.

\section{Revistas femininas e feministas}

Embora a Revista AzMina se autodenomine como uma revista feminista e não feminina, o veículo compreende diversas características desse segmento jornalístico. Dessa forma, destaca-se brevemente a historicidade e as particularidades da imprensa feminina brasileira.

Desde as primeiras publicações datadas do século XIX (BUITONI, 1990), esse tipo de imprensa pode ser interpretado, como afirma Elizabeth Cardoso (2004), enquanto um fenômeno nacional, qualitativo (em virtude de ter divulgado o feminismo), quantitativo (em termos de produções), contínuo e influenciado pelo movimento feminista. Outra característica é a mudança de discurso que acompanha a alteração dos papeis sociais desempenhados pelas mulheres ao longo do tempo (WOLF, 1992).

Por fazer parte dessas modificações, as revistas femininas cumprem tanto a função de "melhor amiga" quanto de "pior inimiga" das mulheres. Isso porque essas revistas acabam sendo os únicos meios de comunicação que levam em conta as Revista Pauta Geral-Estudos em Jornalismo, Ponta Grossa, vol. 6, n. 2, p. 35-52, Jul/Dez, 2019. 


\section{REVISTA PAUTA GERAL}

\section{ESTUDOS EM JORNALISMO}

10.5212/RevistaPautaGeral.v.6.i2.0003

preocupações das mulheres, já que "a cultura em geral adota um ponto de vista masculino do que é noticia ou não. [...] essa mesma cultura também adota um ponto de vista masculino com relação a quem vale a pena ser visto" (WOLF, 1992, p. 92). Além disso, levam as questões do movimento feminista à maioria das mulheres, já que operam em uma lógica de cultura de massas para o público feminino.

Essas potencialidades também se somam à ideia de as revistas oferecerem um "conselho sábio, testado pela experiência, de uma admirável parenta mais velha" (WOLF, 1992, p. 96-97), o que admite uma maior cumplicidade entre o público e o segmento. Mas essa cumplicidade também é alimentada pela sua face negativa, já que reforça o "mito da beleza" e é refém dos anunciantes que buscam padronizar e homogeneizar um tipo específico de mulher como o ideal para consumo, bem como um modelo padronizado de corpo feminino (BRAGA, 2005). Essa ideia de corpo perfeito é discutida por Adriana Braga (2005):

O corpo feminino encontra-se instituído nos produtos midiáticos, e, no caso das revistas femininas, apresenta-se como um composto de "partes" suscetíveis de "melhoramento". Esse processo de territorialização do corpo feminino midiático se faz mediante o aporte de diferentes saberes moral, psicológico, sanitário, médico, estético, mercadológico - que fazem com que a competência dos discursos da imprensa feminina se constitua como um "sistema perito", definindo formas legítimas de apropriação e uso de cada uma dessas partes. (BRAGA, 2005, p. 3)

Diante dessas características, pode-se inferir que os discursos das revistas femininas são compostos por outros valores-notícia. A atualidade da revista, por exemplo, é a atualização do ideal de corpo feminino, da noção de "mulher". É "um frame cultural do feminino" (BRAGA, 2005, p. 22), e isso pode ser percebido inclusive nesses "novos" discursos de revistas feministas como AzMina. Formações discursivas como a mulher "fora do padrão" e a "dona do próprio destino" (ROCHA; BENETTI, 2007), a polarização entre "nós" (mulheres) e "eles" (os outros), característico da ideologia (VAN DIJK, 2008), e o "discurso de sedução" (BRAGA, 2005) que evoca o tempo verbal presente e o diálogo com a leitora são algumas das particularidades que são identificadas na revista analisada, e que vão ao encontro do que é identificado enquanto discurso comum às revistas femininas. 


\title{
REVISTA PAUTA GERAL
}

\section{ESTUDOS EM JORNALISMO}

10.5212/RevistaPautaGeral.v.6.i2.0003

\section{Revista AzMina e o jornalismo que produz conhecimento}

Criada em maio de 2015 por meio de um financiamento coletivo, a Revista AzMina surgiu com a proposta de ser uma fonte de "informação e educação feminista e independente" e "uma publicação online e gratuita para mulheres de A a Z"7. Sendo um projeto da ONG AzMina, uma instituição sem fins lucrativos que promove palestras, consultorias, campanhas e cursos, a revista passou a ser o carro-chefe da associação para o jornalismo investigativo funcionando por meio de crowfundings, assinaturas, recursos de editais e fundações de apoio.

A questão da forma de financiamento e as limitações de ter anunciantes são problematizadas por Naomi Wolf (1992) como o lado negativo das revistas femininas. AzMina não depender deste suporte externo ${ }^{8}$ acaba influindo diretamente no fazer jornalístico. Em entrevista, a cofundadora e diretora executiva, Carolina Oms relata:

\begin{abstract}
Tem diferença de trabalhar sem a preocupação dos anunciantes porque mesmo quando você se propõe, como as revistas femininas hoje se propõe, a falar de feminismo, não adianta você se dizer feminista, mas continuar reforçando os mesmos padrões de moda e beleza do resto das páginas que não são reportagens. Isso oprime e cria padrões inatingíveis do mesmo jeito, e a gente não faz isso na revista, a gente fala de todos os corpos, todas as vivências, todos os espectros e também por essa questão dos anunciantes. (Entrevista concedida por Carolina Oms em janeiro de 2019).
\end{abstract}

Essa não dependência dos anúncios acaba incidindo no conteúdo jornalístico produzido - já que há possibilidade de não se preocupar com a perda de financiamento -, deixando às claras o posicionamento do jornalismo que propõem. Em um vídeo institucional ${ }^{9}$ publicado no canal da revista no Youtube, as jornalistas explicam como fazem uma reportagem investigativa, citando que "na hora de juntar uma reportagem são feitas escolhas: isso se chama linha editorial - que é a posição do veículo. Por mais que

7QUEM SOMOS. AzMina. 2015. Disponível em: <https://azmina.com.br/sobre/quemsomos/>. Acesso em: 18 jan. 2019.

${ }^{8}$ AzMina também faz parcerias com apoiadoras externas, desde que haja a preservação da independência editorial, bem como de critérios de escolha para os possíveis apoios, os quais devem ir ao encontro do proposto ideologicamente pela revista.

${ }^{9}$ AZMINA. Você sabe como é feita uma reportagem investigativa? 2018. Disponível em: <https://www.youtube.com/watch?time continue=3\&amp; $v=f f O o c c 0 H N I E>$. Acesso em: 19 jan. 2019.

Revista Pauta Geral-Estudos em Jornalismo, Ponta Grossa, vol. 6, n. 2, p. 35-52, Jul/Dez, 2019. 


\section{REVISTA PAUTA GERAL}

\section{ESTUDOS EM JORNALISMO}

10.5212/RevistaPautaGeral.v.6.i2.0003

um texto só conte verdades, ele sempre tem um lado (o nosso é contra o machismo!)" (AZMINA, 2018).

Em razão dessa liberdade editorial alcançada por meio da independência, a publicação se organiza de uma maneira divergente às habituais encontradas em revistas femininas, havendo subversão de algumas categorias. A revista é dividida em seções intituladas como "Reportagens" com 15 subseções, "Especiais" e "Opinião"10, com 9 subcategorias que se referem a colunas de mulheres negras, como a "Afronerd" e "Feminismos negros", transgêneros como "Mulher, trans", e uma subseção composta por relatos pessoais, a "Divã d'AzMina". Referindo-se a essa editoria de relatos, Ana Beatriz Silva (2017) argumenta que esse tipo de seção resgata uma reformulação do "correio sentimental" tradicional em revistas femininas. A partir dessa ideia, os aconselhamentos, antes tomados pelo discurso de especialistas, passam a compor uma articulação diferenciada, já que "agora a autoridade desloca-se para o fato da "conselheira" ser feminista, garantindo que os conselhos podem ser empoderadores em vez de reforçarem padrões de gênero" (SILVA, 2017, p. 34).

No que se refere à seção "Reportagens", pode-se perceber uma diversidade de subseções que abordam os mais variados assuntos. "Saúde e sexo", tratando sobre questões ligadas ao corpo e a sexualidade, "Mãezinha, vírgula" sobre maternidade, "Butina" acerca de assuntos LBT são alguns dos exemplos. Gabrielle Bilttelbrun (2018) afirma que essa forma de dispor o conteúdo que AzMina traz se vale dos campos associados ao "ser feminina" e a partir disso os subverte, propondo diferenças, por vezes invisibilizadas, as quais visam consolidar suas proposições feministas.

Sobre a seção "Especiais", o conteúdo jornalístico apresenta reportagens investigativas em profundidade. Entre as 17 reportagens presentes, identifica-se uma ampla variedade de assuntos, tratando desde questões como maternidade indígena e maternidade lésbica até casos de denúncia referentes à exploração sexual de meninas menores de idade. Sobre a escolha de pautas, podemos perceber especificidades no processo produtivo:

\footnotetext{
10Embora a seção "Opinião" seja importante para refletir como se estruturam as ideias da própria revista e de suas colunistas, entendemos que para esta pesquisa se mostra mais valoroso focar nas outras editorias que não se referem a artigos de opinião.
}

Revista Pauta Geral-Estudos em Jornalismo, Ponta Grossa, vol. 6, n. 2, p. 35-52, Jul/Dez, 2019. 


\title{
REVISTA PAUTA GERAL
}

\section{ESTUDOS EM JORNALISMO}

\author{
10.5212/RevistaPautaGeral.v.6.i2.0003
}

\begin{abstract}
A escolha de pautas é baseada no que são as prioridades da revista. Temas que a gente se propõe a falar: direitos humanos, desigualdade, desigualdade do trabalho, questões trans, lésbicas, questões sobre o corpo, gordofobia, sexualidade focando na relação que as mulheres têm com o corpo... Falar de todos os assuntos que podem ser assuntos que a gente toca e também falar um pouco de política, esporte, economia... Mas a única coisa é que tem que ser tratado de uma perspectiva de gênero. É claro que isso acaba dificultando um pouco a escolha das pautas porque quase tudo pode ser pauta, mas a ideia é sempre que a gente traga uma abordagem diferente do que o resto da imprensa traz, que a gente seja mais leve, mais bem humorada, mais informal, mais didática também, não queremos falar para entendidos... Então às vezes a gente até fala de um assunto que está sendo tratado, mas a gente busca dar uma abordagem diferente, que viralize, que seja mais didática. (Carolina Oms, janeiro de 2019)
\end{abstract}

A partir disso, infere-se que por mais diverso que seja o conteúdo, a perspectiva de gênero, fruto de uma ideologia marcada, é determinante para orientar o fazer jornalístico praticado pela AzMina.

Isso pode ser assimilado em reportagens que a priori poderiam ser encontradas em outros veículos jornalísticos, mas que se identificam algumas características próprias de uma perspectiva de gênero. No título de "Guia de investimentos para todas - e não, não precisa ser boa de matemática"11 (grifo nosso), já é possível perceber a que público se destina: mulheres. Além de estabelecer uma relação entre a pauta financeira e a independência e empoderamento feminino, ao longo do texto as orientações para investimentos são semelhantes a outras, mas o diferencial se coloca na escolha das fontes serem mulheres, sendo uma economista e uma couch financeira.

Essa escolha de fontes, que prioriza vozes femininas e relatos pessoais, pode ser apreendida pela maioria dos conteúdos presentes. A questão do uso de turbantes por mulheres brancas, por exemplo, é uma disputa dentro do feminismo. Em "Eu também posso usar turbante?"12 a voz protagonista de uma mulher negra é a fonte consultada, de forma a explicar as raízes dessa discussão e seu posicionamento sobre o tema. A fonte,

\footnotetext{
"OMS, Carolina. Guia de investimentos para todas - e não, não precisa ser boa de matemática. AzMina. 2017. Disponível em: <https://azmina.com.br/reportagens/guia-deinvestimentos-para-todas-e-nao-nao-precisa-ser-boa-de-matematica/>. Acesso em: 26 jan. 2019.

12LUNA, Juliana. Eu também posso usar turbante? AzMina. 2016. Disponível em: $<$ https://azmina.com.br/reportagens/eu-tambem-posso-usar-turbante/>. Acesso em: 26 jan 2019.
}

Revista Pauta Geral-Estudos em Jornalismo, Ponta Grossa, vol. 6, n. 2, p. 35-52, Jul/Dez, 2019. 


\section{REVISTA PAUTA GERAL}

\section{ESTUDOS EM JORNALISMO}

10.5212/RevistaPautaGeral.v.6.i2.0003

além de ser uma mulher, está diretamente imbricada no assunto, o que demonstra as preocupações ideológicas da redação com o comprometimento desse debate cultural.

Retomando ainda a perspectiva de gênero, é interessante trazer o entendimento sobre a que isso realmente se refere. Em "Feminismo e religião: as mulheres que buscaram independência na idade média"13, a reportagem sobre a influência do ambiente religioso nas origens do feminismo traz percepções que muitas vezes estão alheias quando se recupera a historicidade dos estudos sobre a origem do movimento feminista. $A$ ideia de socializar o conhecimento acadêmico, representado pela voz das fontes especializadas entrevistadas (neste caso uma pesquisadora, uma professora doutora em História e uma teóloga doutora em Filosofia e em Ciência da Religião), é uma forma notável de compreender essa posição do jornalismo com perspectiva de gênero ocupando este lugar entre o senso comum e o conhecimento científico.

Em "Fazer cocô: um tabu feminino"14, a reportagem traça uma relação entre o machismo, os hábitos de higiene e a prisão de ventre comum em três a cada cinco mulheres ocidentais. A partir de relatos de experiências pessoais, especialistas de saúde e pesquisadoras, a revista coloca em pauta o questionamento de que "pensar analiticamente sobre isso pode ser uma forma de autoconhecimento e também de lidar com muitas questões do dia-a-dia" (AZMINA, 2018).

Nesse último exemplo, assim como em "Como seria um governo de Bolsonaro para as mulheres?"15, pode-se recorrer à ideia de que a revista enuncia sobre assuntos que são invisibilizados pela mídia tradicional em geral. Isso também pode ser visto no reforço da ideologia pelo uso dos termos "nós" e "eles" (VAN DIJK, 2008):

SD 1: "Diariamente nos vemos expostas a situações de assédio, medo e violência simplesmente por sermos mulheres" (grifo nosso);

\footnotetext{
13LEÃO, Naiara. Feminismo e religião: as mulheres que buscaram independência na idade média. AzMina. 2018. Disponível em: <https://azmina.com.br/reportagens/feminismoreligiao/>. Acesso em: 26 jan 2019.

14Fazer cocô: um tabu feminino. Disponível em: <https://azmina.com.br/reportagens/fazercoco-um-tabu-feminino/>. Acesso em: 26 jan. 2019.

15BRUNO, Maria Martha. Como seria um governo de Bolsonaro para as mulheres? AzMina. 2018. Disponível em: <https://azmina.com.br/reportagens/eleicao-de-bolsonaro-para-asmulheres/>. Acesso em: 26 jan. 2019.
}

Revista Pauta Geral-Estudos em Jornalismo, Ponta Grossa, vol. 6, n. 2, p. 35-52, Jul/Dez, 2019. 


\title{
REVISTA PAUTA GERAL
}

\section{ESTUDOS EM JORNALISMO}

\author{
10.5212/RevistaPautaGeral.v.6.i2.0003
}

SD 2: "O que queremos é envelhecer em paz com nossos corpos, nossas curvas, nossas marcas, pois, a partir do momento em que travamos uma luta contra nós mesmas, a gente já perdeu"16 (grifo nosso).

Por vezes, esse "nós" se transforma em "nós, mulheres negras", ou em "nós, mulheres lésbicas", marcando o discurso que se utiliza do intradiscurso e do interdiscurso que se afirma nos já-ditos feministas ${ }^{17}$ e em uma objetividade feminista situada em um saber localizado (HARAWAY, 1995). Inclusive, essa posição que deixa marcas na produção do discurso pode ser identificada nas palavras da integrante da revista:

Eu sempre me identifiquei como feminista desde que eu conheci o movimento. Na faculdade eu li o livro da Simone de Beauvoir "O Segundo Sexo" e gostei muito. No colégio eu já tinha aprendido algumas pequenas coisas sobre o movimento e achava difícil ser mulher e não se considerar feminista. (Carolina Oms, janeiro de 2019).

Essa posição delimitada, que se ancora nas crenças, ideologias e saberes que constituem a subjetividade objetivada (GENRO FILHO, 2012) do fazer jornalístico da revista, permite que se entenda o conhecimento produzido por elas como comprometido politicamente com a realidade histórico-social e com o jornalismo em sua singularidade. Esse comprometimento também pode ser identificado em algumas reportagens em que o processo de produção é explicitado:

SD 3: "Esta reportagem tinha outra abertura planejada. Mas quando foi passada para o editor de texto, a palavra "pescadoras" foi sublinhada em vermelho, acompanhada por uma sugestão de substituição permanente por "pescadores". O ganho de representatividade na profissão é relativamente recente, mas esse fato aparentemente banal mostra como elas ainda são invisíveis para uma parte da sociedade. Invisíveis até no corretor automático do computador." ${ }^{18}$ (grifo nosso);

\footnotetext{
16RIBEIRO, Maria. Como amar um corpo fora do padrão? Três mulheres toparam esse desafio conosco! 2017.2 Disponível em: $<$ https://azmina.com.br/reportagens/como-amar-um-corpo-fora-do-padrao-tres-mulherestoparam-esse-desafio-conosco/>. Acesso em 26 jan. 2019.

${ }_{17} \mathrm{Em}$ muitas reportagens há inferências como: "Afinal, um dos lemas do feminismo é a sororidade, ou seja, a irmandade entre as mulheres" (grifo nosso). Essa ideia de recuperar os já-ditos por meio da memória discursiva é uma das características presentes recorrentemente no discurso da AzMina.

${ }^{18}$ CALZA, Bia. A luta das pescadoras contra a invisibilidade. AzMina. 2016. Disponível em: $<$ https://azmina.com.br/reportagens/a-luta-das-pescadoras-contra-a-invisibilidade/>.

Acesso em: 26 jan. 2019.
}

Revista Pauta Geral-Estudos em Jornalismo, Ponta Grossa, vol. 6, n. 2, p. 35-52, Jul/Dez, 2019. 


\title{
REVISTA PAUTA GERAL
}

\section{ESTUDOS EM JORNALISMO}

\author{
10.5212/RevistaPautaGeral.v.6.i2.0003
}

\begin{abstract}
SD 4: "Podemos desmarcar a entrevista hoje? Tive que levar meu filho para o médico e só tinha profissional adequado na cidade vizinha, a uma hora de viagem de onde moramos". Essa foi a frase mais ouvida pela reportagem da Revista AzMina nos dois meses que durou a apuração desta série de reportagens."

SD 5: "Podemos desmarcar a entrevista hoje? Tive que levar meu filho para o médico e só tinha profissional adequado na cidade vizinha, a uma hora de viagem de onde moramos". Essa foi a frase mais ouvida pela reportagem da Revista AzMina nos dois meses que durou a apuração desta série de reportagens ${ }^{20 . " ~(g r i f o ~ n o s s o) . ~}$
\end{abstract}

Essas construções demonstram a preocupação com a linguagem como parte do discurso construído. Além de a transparência no fazer jornalístico acentuar a ideia de um jornalismo orientado à produção de conhecimento, afirmar as profissionais como pescadoras que são ou as dificuldades encontradas pelas mães de crianças com microcefalia, marca o caráter ideológico de visibilizar narrativas de mulheres que são excluídas dos meios de comunicação tradicionais.

Outra questão interessante no discurso da revista é colocar em pauta os estereótipos - inclusive os naturalizados pelas próprias feministas. Na reportagem "Precisamos falar sobre aborto - mas não do jeito que você está pensando"21, o estigma do tema é problematizado. Em determinado trecho é dito: "Hoje, no entanto, os tabus que cercam o aborto ainda estão fortemente vivos - inclusive dentro do movimento feminista" (grifo nosso), se referindo a uma ideia negativa associada à dor, ao silêncio e à morte. No texto, advogam em favor de outro estereótipo possível, em que os sentidos do aborto sejam relacionados à escolha, liberdade, empoderamento e tranquilidade. Assim, a revista abre um leque para as possibilidades de leitura sobre um mesmo assunto - mesmo que a leitura predominante compartilhada pelos estereótipos feministas seja outra.

Por fim, para evidenciar a diferença da questão de produção do conhecimento de acordo com a perspectiva de Genro Filho (2012), propõe-se um breve exercício comparativo entre AzMina e outros veículos de comunicação: a Revista IstoÉ, a NSC e o

\footnotetext{
${ }^{19}$ MODELLI, Lais. Nove meses de Zika. E agora? AzMina. 2016. Disponível em: <https://azmina.com.br/especiais/nove-meses-de-zika-e-agora/>. Acesso em: 26 jan. 2019. 20MODELLI, Lais. Nove meses de Zika. E agora? AzMina. 2016. Disponível em: $<$ https://azmina.com.br/especiais/nove-meses-de-zika-e-agora/>. Acesso em: 26 jan. 2019. 21BAHIA, Letícia. Precisamos falar sobre aborto - mas não do jeito que você está pensando. AzMina. 2017. Disponível em: <https://azmina.com.br/reportagens/precisamosfalar-sobre-aborto-mas-nao-do-jeito-que-voce-esta-pensando/>. Acesso em: 26 jan. 2019.
}

Revista Pauta Geral-Estudos em Jornalismo, Ponta Grossa, vol. 6, n. 2, p. 35-52, Jul/Dez, 2019. 


\section{REVISTA PAUTA GERAL}

\section{ESTUDOS EM JORNALISMO}

10.5212/RevistaPautaGeral.v.6.i2.0003

portal Brasil 247. O fato refere-se ao veto do governador de Santa Catarina ao projeto que autoriza pessoas trans e travestis a usarem o nome social em cargos públicos.

$\mathrm{Na}$ reportagem de $A z M i n a^{22}$, há uma explicação detalhada da lei nacional sobre o registro do nome social com fontes especializadas jurídicas. Outra fonte consultada é de um homem transgênero, que é afetado pessoalmente pela medida. Ao longo da reportagem, são expostos posicionamentos anteriores das instituições no mesmo estado a respeito de pautas que fogem à lógica conservadora, além de colocar em perspectiva o que pode vir a ocorrer a partir da decisão tomada.

Já a Revista IstoÉ ${ }^{23}$ não consulta nenhuma fonte e apenas é narrado o veto. $\mathrm{Na}$ $\mathrm{NSC}^{24}$ repete-se o mesmo padrão, e a única fonte consultada é a da procuradoria-geral do Estado. Na página do Brasil $247^{25}$, identifica-se uma pequena mudança: a fonte entrevistada é a presidenta da Comissão de Direito Homoafetivo e Gênero da OAB. Apesar disso, não há mais explicações para além da decisão do governador.

Não pretendemos traçar longas comparações diante desses outros jornalismos, visto que é preciso também levar em conta as especificidades de cada tipo de mídia bem como outras características. Apenas buscamos destacar os atributos que fazem da reportagem da AzMina ser carregada de sentidos que recuperam as categorias filosóficas do singular, particular e universal, e permitem um conhecer maior a partir de um viés crítico sobre o caso. Situar o fato a partir de sua singularidade, rumo a uma filiação contextual que visa abordar diferentes aspectos relacionados ao assunto é um diferencial que pode ser percebido nesse exemplo anteriormente citado.

\section{Considerações finais}

22TOLLER, Luisa. Entenda o veto ao nome social de pessoas trans em serviços públicos em SC. AzMina. 2019. Disponível em: <https://azmina.com.br/reportagens/entenda-o-veto-aonome-social-de-pessoas-trans-em-servicos-publicos-em-sc/>. Acesso em: 29 jan. 2019.

${ }^{23 R E D A C ̧ A ̃ O . ~ G o v e r n a d o r ~ d e ~ S C ~ v e t a ~ n o m e ~ s o c i a l ~ d e ~ t r a v e s t i s ~ e ~ t r a n s e x u a i s ~ e m ~ s e r v i c ̧ o e s ~}$ públicos estaduais. IstoÉ. 2019. Disponível em: <https://istoe.com.br/governador-de-scveta-nome-social-de-travestis-e-transexuais-em-servicos-publicos-estaduais/>. Acesso em: 29 jan. 2019.

24SILVA, Ânderson. Carlos Moisés veta uso do nome social de travestis e transexuais. NSC.

2019. Disponível em: <https://www.nsctotal.com.br/colunistas/anderson-silva/carlosmoises-veta-uso-do-nome-social-de-travestis-e-transexuais-nos>. Acesso em: 29 jan. 2019. ${ }^{25 R E D A C ̧ A ̃ O . ~ G o v e r n a d o r ~ d e ~ S C ~ v e t a ~ u s o ~ d e ~ n o m e ~ s o c i a l ~ a ~ s e r v i d o r e s ~ p u ́ b l i c o s . ~ B r a s i l ~} 247$. 2019. Disponível em: <https://www.brasil247.com/pt/247/brasil/380796/Governador-de-SCveta-uso-de-nome-social-a-servidores-p\%C3\%BAblicos.htm>. Acesso em: 29 jan 2019.

Revista Pauta Geral-Estudos em Jornalismo, Ponta Grossa, vol. 6, n. 2, p. 35-52, Jul/Dez, 2019. 


\section{REVISTA PAUTA GERAL}

\section{ESTUDOS EM JORNALISMO}

10.5212/RevistaPautaGeral.v.6.i2.0003

Ao propor uma análise discursiva que comporta concepções feministas para perceber as questões relacionadas ao jornalismo, logo é perceptível que há visões de mundo hegemônicas, consensuais e legitimadas nas instituições midiáticas. Um fazer jornalístico que envolva um ressignificar do processo produtivo da notícia, a partir de um viés de gênero, é marcado pela ocupação de um lugar outro no jornalismo.

Este lugar é aquele já preconizado por Genro Filho (2012) no final dos anos 1980, no qual se posicionaria um jornalismo com potencial transformador. Trinta anos depois, AzMina se apodera e agrega valores positivos a esse espaço de forma a atualizá-lo, trazendo o viés de gênero também como um potencial crítico que faz parte do comprometimento de um jornalismo que desempenha sua função social na sociedade contemporânea.

Inicialmente, foi um desafio refletirmos sobre o que era um jornalismo orientado pela produção de conhecimento. Como classificar? Como mensurar? Ao propor a análise da Revista AzMina e entendê-la como um veículo que trata sobre pautas voltadas às mulheres - que geralmente estão fora das pautas principais dos veículos tradicionais como afirmado por Wolf (1992) -, compreendemos que o fazer jornalístico produzido já é uma forma de conhecimento por si. Isso porque traz abordagens outras calcadas em uma prática jornalística preocupada em romper com padrões hegemônicos excludentes socialmente estabelecidos também no jornalismo.

O jornalismo de AzMina e sua perspectiva de gênero representam este potencial transformador em muitas partes do material que produzem. Isso ocorre desde as listas de séries e livros feministas, os guias didáticos para "não ser um babaca" ou na socialização de saberes restritos até então ao meio acadêmico, em uma linguagem clara e acessível a quem se destina. Um jornalismo feminista que se mostra combativo, ideologicamente comprometido e posicionado, é uma das formas de se fazer conhecer mulheres e assuntos invisibilizados pela mídia tradicional e, de fato, de fazer valer a ideia de uma prática orientada pela ideia de conhecimento.

\section{Referências}

BENETTI, Marcia. Análise de Discurso como método de pesquisa em comunicação. In: MOURA, Cláudia Peixoto; LOPES, Maria Immacolata (org.). Pesquisa em comunicação: Metodologias e práticas acadêmicas. Porto Alegre: Editora Universitária da Pucrs, 2016. 


\section{REVISTA PAUTA GERAL}

\section{ESTUDOS EM JORNALISMO}

10.5212/RevistaPautaGeral.v.6.i2.0003

BITTELBRUN, Gabrielle. Cores e contornos: gênero e raça em revistas femininas do século 21. Florianópolis: Insular, 2018.

BRAGA, Adriana. Corpo e agenda na revista feminina. Cadernos IHU Idéias, São Leopoldo, ano 3, n. 40, 2005.

BUITONI, Dulcília. Imprensa feminina. São Paulo: Ática, 1990.

CARDOSO, Elizabeth. Imprensa feminista brasileira pós-1974. Estudos Feministas, Florianópolis, v. 12, 2004.

CHARAUDEAU, Patrick. O que quer dizer informar. In: CHARAUDEAU, Patrick. Discurso das mídias. São Paulo: Contexto, 2018.

GENRO FILHO, Adelmo. O Segredo da Pirâmide: para uma teoria marxista do jornalismo. Florianópolis: Insular, 2012.

GROTH, Otto. O poder cultural desconhecido: fundamentos das ciências dos jornais (periodística). Petrópolis: Vozes, 2011.

HARAWAY, Donna. Saberes localizados: A questão da ciência para o feminismo e o privlégio da perspectiva parcial. Cadernos pagu, Campinas, n. 5, 1995.

LIPPMANN, Walter. Parte III. Estereótipos. In: LIPPMANN, Walter. Opinião Pública. Petrópolis: Vozes, 2008.

LOURO, Guacira Lopes. Gênero, sexualidade e educação: uma perspectiva pósestruturalista. Petrópolis: Vozes, 1997.

MACEDO, Ana Gabriela. Mulheres, arte e poder: uma narrativa de contra-poder? Revista Estudos de Literatura Brasileira Contemporânea, Brasília, n. 37, 2011.

MEDITSCH, Eduardo. O jornalismo é uma forma de conhecimento? Media\&Jornalismo, Coimbra, v. 1, n. 1, out. 2002.

NARVAZ, Martha; KOLLER, Sílvia. Metodologias feministas e estudos de gênero:

articulando pesquisa, clínica e política. Psicologia em Estudo, Maringá, v. 11, n. 3, 2006.

PARK, Robert. A notícia como forma de conhecimento: um capítulo dentro da sociologia do conhecimento. In: BERGER, Christa; MAROCCO, Beatriz (org.). A era glacial do Jornalismo: teorias sociais da imprensa. Porto Alegre: Sulina, 2008.

PONTES, Felipe. O Jornalismo como forma de conhecimento. In: PONTES, Felipe. Adelmo Genro Filho e a Teoria do Jornalismo. Florianópolis: Insular, 2012.

ROCHA, Patricia; BENETTI, Marcia. Jornalismo e modelos de mulher: a construção de sentidos das narradoras de TPM. Revista Contracampo, Rio de Janeiro, v. 23, 2007. 
REVISTA PAUTA GERAL

ESTUDOS EM JORNALISMO

10.5212/RevistaPautaGeral.v.6.i2.0003

SCOTT, Joan. Gênero: uma categoria última para análise histórica. Nova York, Columbia University Press, 1989.

SILVEIRINHA, Maria João. Repensar as políticas públicas sobre as mulheres e os media - ou do quão cruciais são os estudos feministas da comunicação. Ex Aequo, Lisboa, n. 25, 2012.

VAN DIJK, Teun. News, Discourse, and Ideology. 2008.

VEIGA DA SILVA, Marcia. Masculino, o gênero do jornalismo: modos de produção das notícias. Florianópolis: Insular, 2014.

WOLF, Naomi. O mito da beleza: como as imagens de beleza são usadas contra as mulheres. Rio de Janeiro: Rocco, 1992.

ZIRBEL, Ilze. Estudos feministas e estudos de gênero no Brasil. 2007. Dissertação (Programa de Pós-Graduação em Sociologia Política) - Universidade Federal de Santa Catarina, UFSC. Florianópolis, 2007.

Recebido em: 30/09/2019

Aprovado em: 22/11/2019 